\title{
Tertiary cytoreductive surgery in a case of platinum sensitive recurrent ovarian cancer
}

\begin{abstract}
We report a case of platinum sensitive recurrent ovarian cancer. The patient was 44 years old and presented to us on 11/4/14, with an abdominal mass and raised CA-125 levels. She was diagnosed as a case of stage IIIc ovarian cancer after staging debulking laparotomy where we achieved complete cytoreduction (CC-0). She received 6 cycles of platinum based chemotherapy. After a Platinum free interval (PFI) of 1 year, she developed recurrence, which was asymptomatic and was detected by increasing CA-125 levels on routine follow up. Imaging studies revealed localized recurrence with absence of ascites and she had a good performance status. She underwent secondary CRS with HIPEC (CC-0) followed by 6 cycles of platinum based chemotherapy. After a PFI of 16 months, she again developed a second asymptomatic recurrence, manifested by rising CA-125 levels and limited disease on imaging. Her good performance status was maintained and we again offered her a tertiary cytoreductive surgery and were again able to achieve a complete cytoreduction $(\mathrm{CC}-0)$. She was again put on platinum based chemotherapy and has received 2 cycles of lipodox and cisplatin till date and is doing well.
\end{abstract}

Keywords: Recurrent ovarian cancer, Tertiary cytoreduction, Complete cytoreduction
Volume 9 Issue I - 2018

\author{
Vandana Jain, Rupinder Sekhon, Imaduddin \\ Ali, Sudhir Rawal \\ Uro-Gynae Oncology, Rajiv Gandhi Cancer Institute and \\ Research Centre, India
}

\begin{abstract}
Correspondence: Vandana Jain, Fellow Gynecologic Oncology, Rajiv Gandhi Cancer Institute and Research Centre, Sector 5, Rohini, New Delhi, India, Tel 919910700788, Fax 91 I I 2705 I037, Email dr.vandana.j@gmail.com
\end{abstract}

Received: September 27, 2017 | Published: January 31, 2018
Abbreviations: PFI, Platinum Free Interval; B/L, Bilateral; TAH, Total Abdominal Hysterectomy; CRS, Cytoreductive Surgery

\section{Introduction}

Ovarian cancer is the leading cause of death from gynecological cancers in developed world, and majority of patients are diagnosed at advanced stage. ${ }^{1}$ Although about $80 \%$ of patients will achieve complete clinical remission after initial cytoreductive surgery and platinum based combination chemotherapy, about $75 \%$ of them will develop recurrence despite response to initial treatment. ${ }^{2}$

Standard treatment of patients with recurrent ovarian cancer is poorly defined. Most of the patients with recurrent ovarian cancer are treated with salvage chemotherapy regimens, but they are not as effective as first line therapy. Several studies have evaluated the role of secondary and tertiary cytoreductive surgery in these patients, but the role of cytoreduction in recurrent ovarian cancer remains controversial.

The present case report shows the impact of secondary cytoreductive surgery and technical feasibility of tertiary cytoreductive surgery in recurrent ovarian cancer.

\section{Case presentation}

A 44-year-old, non - diabetic, non -hypertensive lady, P2L2 (para 2, live 2), presented to our institute on 11/4/14, with the chief complaint of mass in lower abdomen. Her height was $158 \mathrm{~cm}$; weight was $55 \mathrm{~kg}$ and BMI of $22 \mathrm{Kg} / \mathrm{m}^{2}$. Her cycles were regular, with the last menstrual period on 10/4/14. Her performance status according to Eastern Cooperative Oncology Group (ECOG) was 0. On perabdominal examination a large mass arising from the pelvis was present along with ascites. On per vaginal and rectal examination, a bimanually palpable mass about 14-15 weeks' gravid uterus size was present. Her CA125 level was $549 \mathrm{U} / \mathrm{ml}$, CEA was $0.34 \mathrm{ng} / \mathrm{ml}$ and CA
19-9 was $11.3 \mathrm{u} / \mathrm{ml}$. X-ray chest was normal. CT scan whole abdomen showed a heterogeneously enhancing soft tissue lesion $8.8 \times 5.3 \mathrm{~cm}$ in the left adenexa, omental caking and peritoneal thickening along right perihepatic regions. There was no lymph nodal involvement (Figures $1 \mathrm{~A} \& 1 \mathrm{~B}$ ). The patient underwent primary cytoreductive surgery on $14 / 4 / 14$. TAH+ removal of $\mathrm{B} / \mathrm{L}$ adenexal masses + removal of deposits in pouch of Douglas + pelvic peritonectomy $+\mathrm{B} / \mathrm{L}$ Pelvic lymph node dissection+ Supracolic omentectomy+ Rt sub phrenic peritonectomy + appendicectomy was done and optimal debulking (CC-0) was achieved. The final histopathology was suggestive of high grade serous carcinoma bilateral ovaries, stage IIIc. Patient received 6 cycles of paclitaxel $\left(175 \mathrm{mg} / \mathrm{m}^{2}\right)$ and Carboplatin (AUC-5) till 28/8/14. Following 6 cycles of chemotherapy, CA125 was $11.6 \mathrm{U} / \mathrm{ml}$ and $\mathrm{CT}$ scan suggested no residual/recurrent disease.

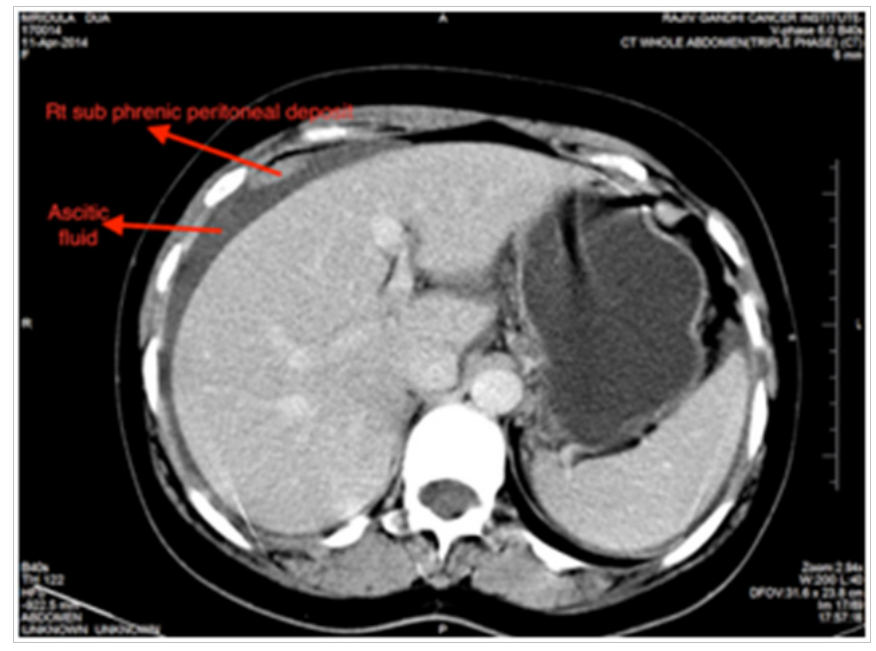

Figure IA CT scan film at first presentation showing sub phrenic peritoneal deposit. 


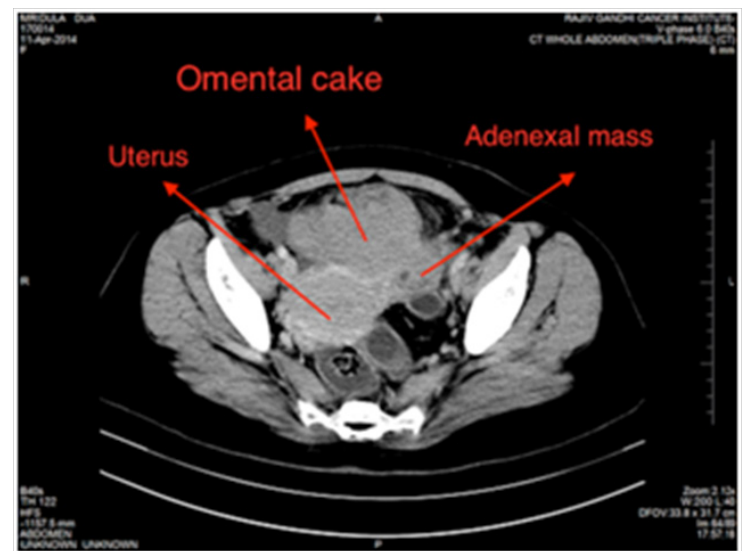

Figure IB CT scan film at first presentation showing adenexal mass and omental cake.

After completion of chemotherapy, patient was put on 3 monthly follow up. At every follow up visit history of any symptoms related to recurrence was taken, patient was examined, and investigations (chest X-ray, USG whole abdomen, CA-125 and vault smear) were done.

\section{First recurrence}

On routine follow up visit, patient had asymptomatic rise in CA125 levels. Her CA-125 was $7 \mathrm{U} / \mathrm{ml}$ on $21 / 3 / 15$; it rose to $17.8 \mathrm{U} /$ $\mathrm{ml}$ on $17 / 6 / 15$ though her imaging was normal. So, she was put on 3 monthly follow up. Her CA-125 was $60.8 \mathrm{U} / \mathrm{ml}$ on 26/9/15. PET$\mathrm{CT}$ was done which showed FDG avid soft tissue deposits along the medial and lateral walls of ascending colon $(3.9 \times 2.8 \mathrm{~cm}$, SUV max 8.0) and in left iliac fossa (Figures 2A \& 2B). Since her PFI was 1 year and her ECOG performance status was 0, she was given the option of (Secondary cytoreductive surgery +/- HIPEC)/ palliative chemotherapy. After proper counselling patient was taken up for surgery. Per-operatively- there was no ascites, there was a growth involving ascending colon, transverse colon with the mesocolon about $12 \times 8 \mathrm{~cm}$, tumor deposits were present in falciform ligament and lesser omentum, and two tumor deposits were present in sigmoid and rectum $5 \times 4 \mathrm{~cm}$ and $4 \times 3 \mathrm{~cm}$. she underwent Sec CRS (Rt hemicolectomy+ ileo-colic anastomosis + anterior resection with Colo-rectal anastomosis + removal of disease deposits on falciform ligament and lesser omentum) + HIPEC (intraperitoneal Cisplatin 50 $\mathrm{mg} / \mathrm{m}^{2}$ and Doxorubicin $15 \mathrm{mg} / \mathrm{m}^{2}+$ intravenous Ifosfamide $1300 \mathrm{mg} /$ $\mathrm{m}^{2}$ for 90 minutes) on $5 / 10 / 15$. Her peritoneal cancer index was 7 and we achieved optimal cytoreduction (CC-0). On histopathology, mesenteric deposits in ascending colon and transverse colon, deposits in lesser omentum, mesenteric deposits in sigmoid colon and rectum, all were positive for high grade serous carcinoma. Patient received 3 cycles of paclitaxel and carboplatin followed by 3 cycles of paclitaxel and cisplatin, since she developed hypersensitivity to carboplatin. Following 6 cycles chemotherapy, her CT scan was normal and CA125 was $<5.5 \mathrm{U} / \mathrm{ml}$. She was again put on 3 monthly follow up.

\section{Second recurrence}

Patient came for routine follow up to the outpatient department on 24/6/17. Patient was asymptomatic. Her examination findings were normal. Her CA125 on $24 / 6 / 17$ was $16.6 \mathrm{U} / \mathrm{ml}$ (CA125 on $11 / 3 / 17$ was $6.9 \mathrm{U} / \mathrm{ml}$. USG revealed 2 hypoechoic lesions in perihepatic space, largest $3 \times 2 \mathrm{~cm}$. PET-CT and CT scan revealed peritoneal deposits along the caudate lobe $(2.7 \times 2.6 \mathrm{~cm})$ and perisplenic deposit and a large ventral abdominal wall hernia (Figure 3). Since her PFI was 16 months and she maintained a good performance status (ECOG 0 ), she was counselled and taken up for tertiary CRS on 6/7/17. Peroperatively, a $6 \times 7 \mathrm{~cm}$ deposit was present near segment $\mathrm{V}$ of liver, $3 \times 2 \mathrm{~cm}$ deposit was present adherent to gall bladder and another $4 \times 3$ $\mathrm{cm}$ deposit was present near the splenic hilum. There was no ascites. An optimal cytoreduction (CC-0) was again achieved after removing the gall bladder with the perisplenic and caudate lobe deposit. On histopathology, gall bladder, perisplenic and caudate lobe deposits were all positive for high grade serous carcinoma. After discussion with medical oncologists, the patient was started on Lipodox and Cisplatin based chemotherapy and presently she has received 2 cycles till 28/8/17 and is doing well.

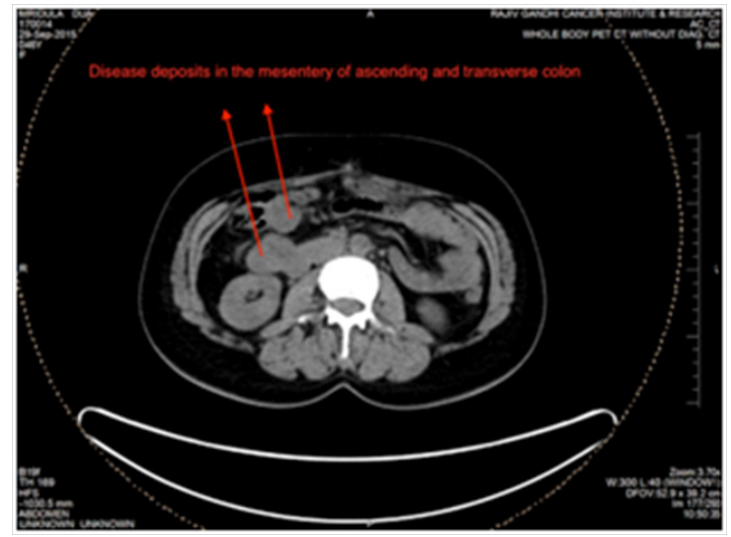

Figure 2A CT scan film at first recurrence showing mesenteric deposits.

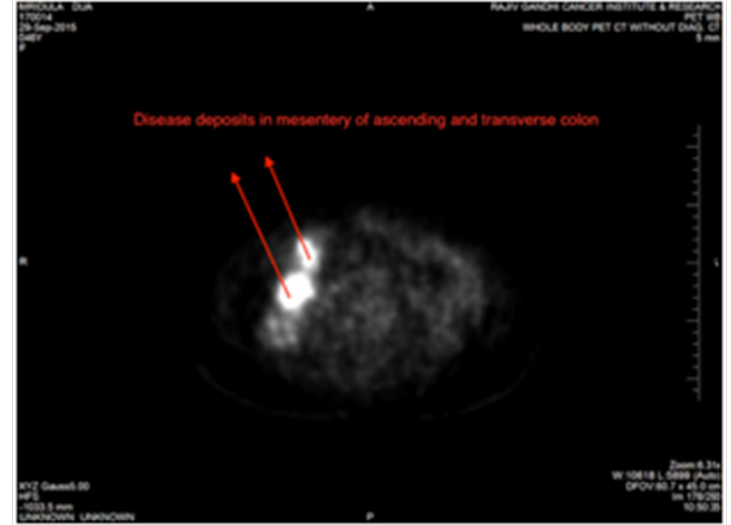

Figure 2B PET-CT film at first recurrence showing mesenteric deposits.

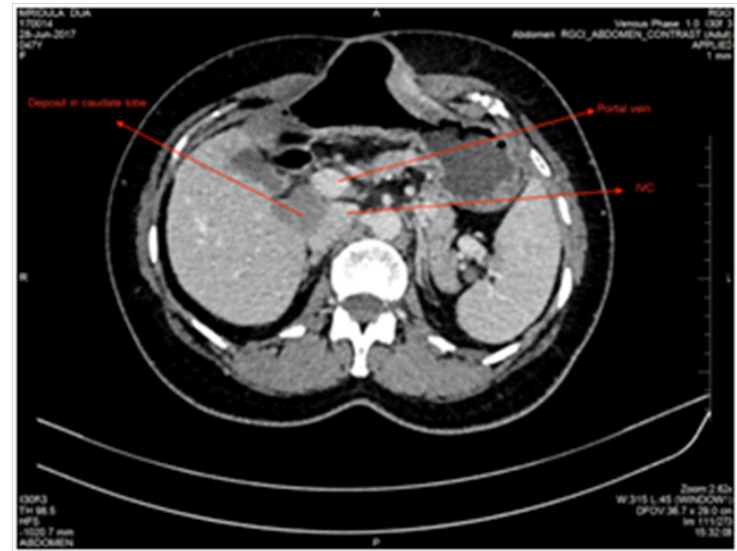

Figure $3 \mathrm{CT}$ scan film at second recurrence showing deposit at caudate lobe of liver. 


\section{Discussion}

Despite optimal treatment including complete cytoreduction followed by adjuvant platinum-paclitaxel chemotherapy, 5-year survival for advanced ovarian cancer is about 30\%. ${ }^{3}$ About $75 \%$ ovarian cancer patients will develop recurrence within 2 years and the mean 5-year survival after radiologically defined recurrence is less than $10 \%{ }^{4}$ The role of cytoreductive surgery as a therapeutic modality for recurrent ovarian cancer is controversial. Even in this setting, achievement of a complete debulking seems to be of upmost importance. ${ }^{5}$ Good performance status, together with no residual disease at primary surgery and absence of ascites are the three factors making the AGO score, to predict complete cytoreduction in a secondary setting. ${ }^{6,7}$

In our case report the patient underwent complete cytoreduction in her primary surgery. She developed asymptomatic recurrence after a platinum free interval of 1 year with limited disease on imaging, her ECOG performance status was 0 at first recurrence and there was no ascites. She fulfilled all the criteria of the Arbeitsgemeinschaft Gynaekologische Onkologie (AGO) score and we were able to achieve complete debulking with no gross residual disease.

Patients who enter a second remission following their initial recurrence will eventually relapse. Data on tertiary cytoreductive surgery are even more limited than those in the secondary setting. ${ }^{8-11}$ All the studies conclude that tertiary cytoreductive surgery offers a survival benefit in highly selected group of patients, with the greatest benefit observed in patients in whom complete cytoreduction could be achieved. The various studies on tertiary cytoreduction have quoted a morbidity rate varying from $15-31 \%$.

In a large multicenter trial, complete tertiary cytoreduction was the most potent predictor of survival followed by FIGO stage I-II at initial diagnosis, exclusive retroperitoneal recurrence and Tertiary CRS performed ${ }^{3} 3$ years after primary diagnosis. Presence of single lesion and good performance status (ECOG 0) were the only independent predictors of complete cytoreduction. ${ }^{12}$

In our case report, the second recurrence was also asymptomatic and occurred at an interval of more than 3 years after the initial diagnosis. Patient had a good performance status (ECOG-0) and the disease was limited to three sites with absence of ascites. We could again achieve complete cytoreduction and there was no post-operative morbidity.

In conclusion, tertiary cytoreductive surgery can be offered to selected patients with good clinical condition in whom complete cytoreduction seems to be feasible in centers with the required expertise to perform complex surgical procedures.

\section{Acknowledgements}

We would like to say special thanks to Dr. Atul Patil for providing the radiology images to us.

\section{Conflicts of Interest}

No financial interest or conflicts of interest exist.

\section{References}

1. Jemal A, Siegel R, Xu J, et al. Cancer statistics, 2010. CA: A Cancer J Clin. 2010;60(5):277-300.

2. Ozols RF. Recurrent ovarian cancer: evidence-based treatment. J Clin Oncol. 2002;20(5):1161-1163.

3. Heintz APM, Odicino F, Maisonneuve P, et al. Carcinoma of the ovary. Int J Gynecol Obstet. 2003;83(suppl 1):135-166.

4. Cannistra SA. Cancer of the ovary. N Engl J Med. 2004;351(24):25192529.

5. Bristow RE, Puri I, Chi DS. Cytoreductive surgery for recurrent ovarian cancer: a meta-analysis. Gynecol Oncol. 2009;112(1):265-274.

6. Harter P, Bois A, Hahmann M, et al. Surgery in recurrent ovarian cancer: the Arbeitsgemeinschaft Gynaekologische Onkologie (AGO) DESKTOP OVAR trial. Ann Surg Oncol. 2006;13(12):1702-1710.

7. Harter P, Sehouli J, Reuss A, et al. Prospective validation study of a predictive score for operability of recurrent ovarian cancer: the Multicenter Intergroup Study DESKTOP II. A project of the AGO Kommission OVAR, AGO study group, NOGGO, AGO- Austria, and MITO. Int J Gynecol Cancer. 2011;21(2):289-295.

8. Fotopoulou C, Zang R, Gultekin M, et al. Value of tertiary cytoreductive surgery in epithelial ovarian cancer: an international multicenter evaluation. Ann Surg Oncol. 2013;20(4):1348-1354.

9. Hizli D, Boran N, Yilmaz S, et al. Best predictors of survival outcome after tertiary cytoreduction in patients with recurrent platinum sensitive epithelial ovarian cancer. Eur J Obstet Gynecol Reprod Biol. 2012;163(1):71-75

10. Shih KK, Chi DS, Barakat RR, et al. Tertiary cytoreduction in patients with recurrent epithelial ovarian, fallopian tube, or primary peritoneal cancer: an updated series. Gynecol Oncol. 2010;117(2):330-335.

11. Karam AK, Santillan A, Bristow RE, et al. Tertiary cytoreductive surgery in recurrent ovarian cancer: Selection criteria and survival outcome. Gynecol Oncol. 2007;104(2):377-380.

12. Falcone F, Scambia G, Benedetti Panici P, et al. Tertiary cytoreductive surgery in recurrent epithelial ovarian cancer: A multicenter MITO retrospective study, Gynecol Oncol. 2017;147(1):66-72. 